\title{
ANÁLISE DO PROCESSO DE OZONIZAÇÃO PARA TRATAMENDO DE ESGOTO SANITÁRIO SINTÉTICO
}

Maria Zizi Martins Mendonça - maria.zizi@hotmail.com

Universidade Federal de Uberlândia

Andressa de Moura Silva - andressademoura.s@gmail.com

Universidade Federal de Uberlândia

Camila Marques Alves Aguiar-camila.aguiiar@hotmail.com

Universidade Federal de Uberlândia

Márcio Ricardo Salla - mrsalla@feciv.ufu.br

Universidade Federal de Uberlândia 


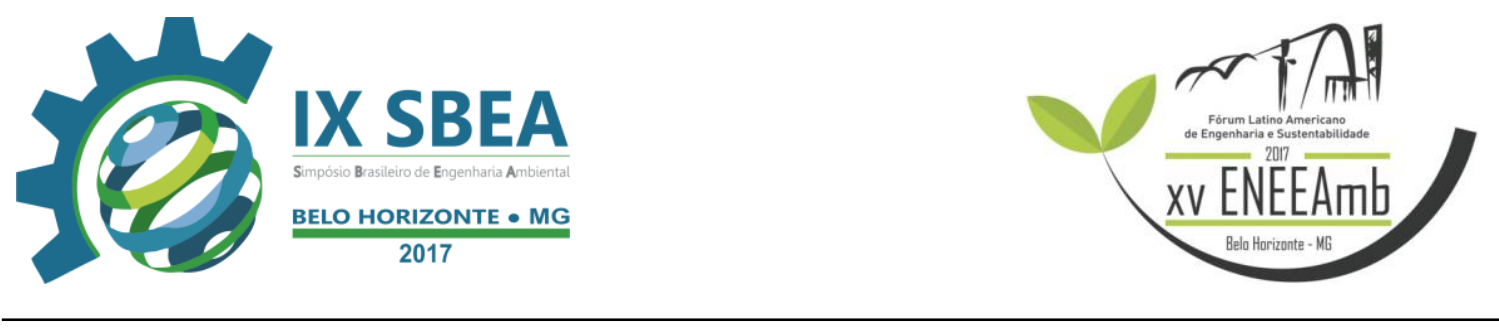

\section{RESUMO}

As estações de tratamento de esgoto (ETE) brasileiras raramente aplicam aos seus efluentes o tratamento terciário, uma etapa de polimento e desinfecção que remove organismos patogênicos, nutrientes e matéria orgânica restantes. A importância deste refinamento se destaca frente a escassez de água e o aumento da poluição nos corpos hídricos. Diversas tecnologias podem ser usadas para realizar a desinfecção de efluentes sanitários, dentre elas destaca-se a ozonização. O gás ozônio tem um alto poder oxidante e não gera produtos residuais tóxicos. Este trabalho apresenta o desempenho de um sistema de ozonização no tratamento de esgoto sanitário sintético, objetivando simular o efluente real esgoto doméstico. O sistema é composto por um ozonizador que produz gás ozônio a partir da injeção de oxigênio por um cilindro, o ozônio passa por um rotâmetro que permite controlar a vazão de gás entre 60 e $300 \mathrm{~L} / \mathrm{h}$. O gás é injetado em uma coluna de acrílico transparente de 1,5 m de altura e $100 \mathrm{~mm}$ de diâmetro interno, o difusor microporoso localizado na entrada de gás da coluna faz com que o ozônio seja borbulhado e difundido pelo efluente. Devido a toxicidade do gás ozônio, dois frascos lavadores de gás contendo $2 \mathrm{~L}$ de solução de iodeto de potássio a $2 \%$, cada um lavando o ozônio que não reagiu com o efluente e liberando oxigênio para atmosfera. Em pH in natura para o efluente, foram avaliados os parâmetros: cor verdadeira, turbidez, pH e DQO para as vazões de gás 60, 120, 180, 240 e $300 \mathrm{~L} / \mathrm{h}$ e os tempos 5, 10, 20, 40 e 60 min. A configuração de tratamento aplicada que apresentou maior eficiência de remoção foi a com vazão de $300 \mathrm{~L} / \mathrm{h}$ e tempo de contato de $60 \mathrm{~min}$, resultando em uma remoção de 78,26\% de cor, 68,8\% de turbidez e 59,9\% de DQO. A ozonização se mostrou um processo eficiente para o tratamento de esgoto sanitário sintético, podendo, futuramente, ser expandido ao tratamento do efluente real correspondente.

Palavras-chave: Ozonização, Esgoto sanitário, Esgoto doméstico.

\section{INTRODUÇÃO/OBJETIVO}

A emissão de efluentes líquidos sem tratamento em rios, lagos e mares vem se tornando um problema ambiental que tem provocado a escassez e a degradação dos 


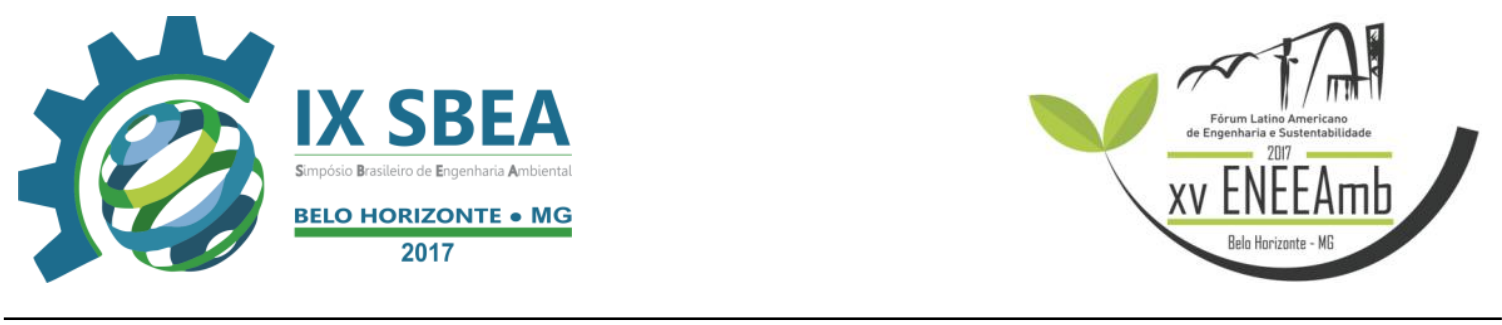

recursos hídricos. Esta diminuição da disponibilidade de água, em função do aumento na demanda de água, da diminuição em sua qualidade e de uma má distribuição espacial dos recursos hídricos e da população, evidencia a necessidade de uma nova abordagem na gestão e exploração destes recursos, que incorpore princípios de sustentabilidade e de produção mais limpa.

O tratamento oferecido aos esgotos sanitários pela maioria das ETE brasileiras compreende três etapas: tratamento preliminar, primário e secundário. $\mathrm{O}$ tratamento terciário, que consiste em uma fase de desinfecção, raramente é empregado. Esta terceira etapa dá polimento ao efluente, removendo organismos patogênicos, matéria orgânica e nutrientes restantes (GARRAFA, 2009; OLIVEIRA, 2006; VON SPERLING, 2014). O cenário atual caminha para uma necessidade cada vez maior de se reutilizar de esgotos tratados e lançar efluentes de melhor qualidade nos corpos receptores, visando uma autodepuração mais rápida dos corpos hídricos. Nesse sentido, tecnologias eficientes devem ser empregadas no polimento dos esgotos tratados.

A resolução CONAMA $n^{\circ} 430$ de 2001 e a Deliberação Normativa COPAM/CERH 01 de 2008 dispõem sobre condições e padrões de lançamento de efluentes. Estas normas estabelecem os efluentes de sistemas de tratamento de esgotos sanitários só podem ser lançados diretamente no corpo receptor se apresentarem $\mathrm{pH}$ entre 6 e 9 e DQO menor que $180 \mathrm{mg} / \mathrm{L}$. Estas normas não preconizam limites para turbidez e cor.

A cloração é, mundialmente, o método mais utilizado no processo de desinfecção de águas residuárias antes de seu lançamento em corpos d'água. Sua popularidade ocorre devido a facilidade de produção, armazenamento, transporte, aplicação e pelo baixo custo deste desinfetante. Entretanto, há algumas décadas, foram descobertas características negativas do cloro, principalmente pelo fato de que seu uso leva a formação de trialometanos (THMs), que são prejudiciais à saúde (WHITE, 1999).

O ozônio tem um alto potencial de oxidação (2,07 Volts), contra os 1,36 Volts do cloro. Outra vantagem da ozonização com relação a cloração é a não geração de subprodutos tóxicos (BERNAL-MARTINEZ et al., 2007). Soares (2007), afirma que a ozonização possui um alto poder de remoção de matéria orgânica carbonácea, cor, 
turbidez, odor e sabor. Seu alto poder oxidante transforma grupos funcionais orgânicos e organometálicos em subprodutos de menor peso molecular e maior biodegradabilidade.

Diante a necessidade de tecnologias de desinfecção altamente eficientes e devido as vantagens do gás ozônio frente o cloro, o presente trabalho avaliou a eficiência da ozonização convencional e sua a capacidade oxidava na remoção de matéria orgânica carbonácea por meio dos parâmetros DQO, cor verdadeira e turbidez.

\section{METODOLOGIA}

\subsection{Caracterização do efluente sanitário sintético}

Em cada ensaio foram inseridos na coluna de ozonização quatro litros de substrato sintético, cuja composição busca se assemelhar ao máximo ao esgoto sanitário. O substrato sintético foi preparado conforme os procedimentos descritos por Torres (1992) apud Oliveira (2001). Simulando a proteína, foi usado 208mg/L de extrato de carne; simulando carboidratos foram adicionados $36 \mathrm{mg} / \mathrm{L}$ de glicose e 112 $\mathrm{mg} / \mathrm{L}$ de amido comercial, como lipídeos, foi adicionado $0,055 \mathrm{mg} / \mathrm{L}$ de óleo de soja emulsionado com 3 gotas de detergente. Além desses compostos, também foi adicionado ao efluente sintético $25 \mathrm{mg} / \mathrm{L}$ de ureia para o aumento da concentração de nitrogênio, $200 \mathrm{mg} / \mathrm{L}$ de bicarbonato de sódio para a manutenção do pH e $5 \mathrm{mg} / \mathrm{L}$ de solução de sais $\left(\mathrm{NaCl}, \mathrm{MgCl}_{2} \cdot 6 \mathrm{H}_{2} \mathrm{O}\right.$ e $\left.\mathrm{CaCl}_{2} \cdot 2 \mathrm{H}_{2} \mathrm{O}\right)$.

O efluente era produzido logo antes de cada ensaio, em baldes plásticos, a temperatura ambiente, usando água do sistema de abastecimento público.

\subsection{Aparato experimental}

A instalação experimental construída para o desenvolvimento desta pesquisa foi montada no Laboratório de Saneamento no campus Santa Mônica da Faculdade Federal de Uberlândia, onde foram realizados ensaios de desinfecção.

Os componentes básicos desta instalação, podem ser visualizados na Figura $1 \mathrm{e}$ são: equipamento ozonizador (a), cilindro de gás $\left(\mathrm{O}_{2}\right.$ puro) ou ar comprimido (b), um rotâmetro (c), uma coluna de ozonização construída com acrílico transparente de 1,5 m 
de altura, $100 \mathrm{~mm}$ de diâmetro interno e $5 \mathrm{~mm}$ de espessura (d), difusores micro porosos para geração de bolhas ascensionais de ozônio com diâmetros menores que 3 mm (e). Frascos em série lavadores de gás (f).

O sistema funciona da seguinte forma: o ozonizador produz gás ozônio a partir da injeção de oxigênio por um cilindro, o ozônio passa por um rotâmetro que permite controlar a vazão de gás entre 60 e $300 \mathrm{~L} / \mathrm{h}$. O gás é injetado em uma coluna de acrílico transparente e o difusor microporoso localizado na entrada de gás da coluna faz com que o ozônio seja borbulhado e difundido pelo efluente. Devido a toxicidade do gás ozônio, dois frascos lavadores de gás contendo $2 \mathrm{~L}$ de solução de iodeto de potássio a $2 \%$, cada um lavando o ozônio que não reagiu com o efluente e liberando oxigênio para atmosfera.

Figura 1 - Aparato experimental

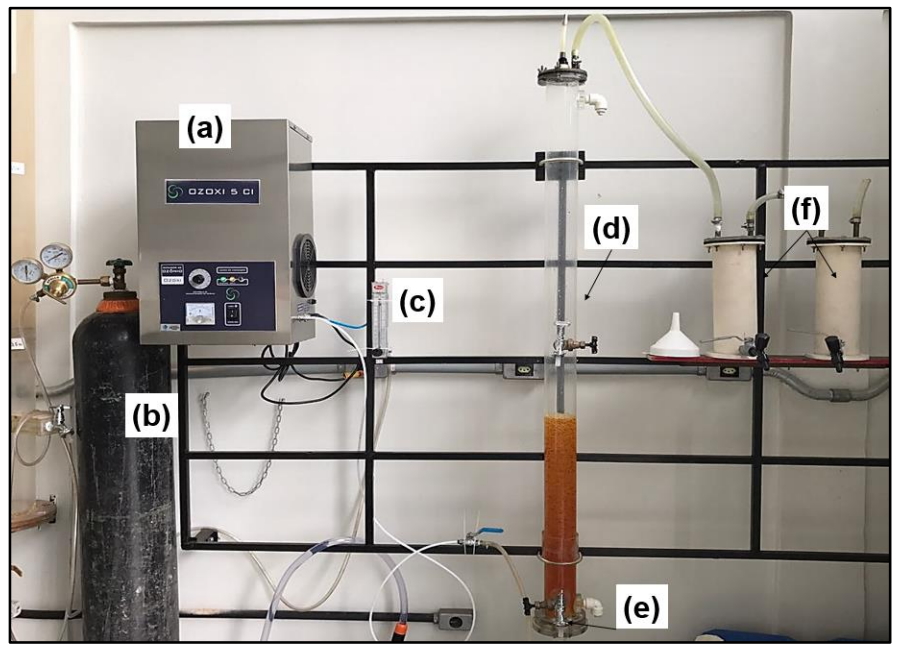

Fonte: Autores (2017)

\subsection{Calibração do Aparato Experimental}

Para determinar a produção do gerador de ozônio em $\mathrm{gO}_{3} / \mathrm{h}$ foi utilizado o método iodométrico, elucidado no Standard Methods for Examination of Water and Wastewater (APHA, 1998).

\subsection{Ozonização}




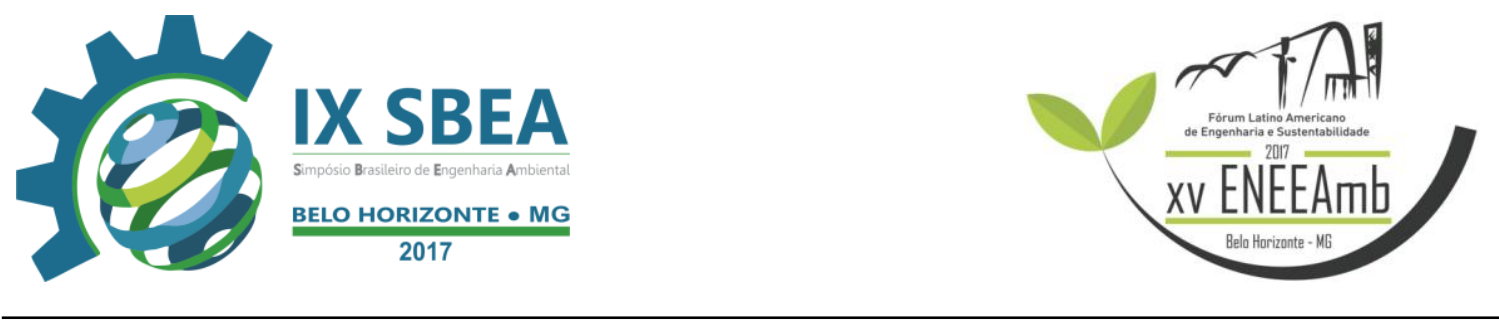

Os ensaios para estudo da ozonização do efluente sintético foram realizados para efluentes com o pH real (neutro), paras vazões de gás afluente de 60, 120, 180, 240 e $300 \mathrm{~L} / \mathrm{h}$ e tempos de contato de 5, 10, 20, 40 e 60 minutos, utilizando o oxigênio (99,95\% de pureza) como gás para abastecer o ozonizador e gerar o gás ozônio. A amostra "branco" era coletada antes de se iniciar o processo de borbulhamento e em seguida, uma amostra era coletada ao atingir cada tempo de contato pré-determinado.

Todos os ensaios físico-químicos foram executados no Laboratório de Saneamento da Faculdade de Engenharia Civil, da Universidade Federal de Uberlândia, conforme diretrizes definidas na NBR 9898 de 1987, presentes na Tabela 1.

Tabela 1 - Parâmetros, metodologia e equipamentos utilizados para execução dos ensaios físico-químicos

\begin{tabular}{|c|c|c|c|c|}
\hline Parâmetros & Unidade & Método de Análise & Equipamentos & Precisão \\
\hline pH & - & $\begin{array}{c}\text { Potenciométrico 4500-H } \\
\text { (APHA, 2005) }\end{array}$ & $\begin{array}{c}\text { Phmetro digital } \\
\text { microprocessado }\end{array}$ & $\pm 0,01 \%$ \\
\hline DQO & $\mathrm{mg} \mathrm{O}_{2} / \mathrm{L}$ & $\begin{array}{c}\text { Colorimétrico por refluxo } \\
\text { fechado 5220 D (APHA, 2005) }\end{array}$ & $\begin{array}{c}\text { Bloco digestor de DQO } \\
\text { espectrofotômetro UV-VIS }\end{array}$ & $\pm 20,0 \%$ \\
\hline Turbidez & UNT & $\begin{array}{c}\text { Nefelométrico 2130 B (APHA, } \\
\text { 2005) }\end{array}$ & Turbidímetro digital & $\pm 2 \%$ \\
\hline $\begin{array}{c}\text { Cor } \\
\text { Verdadeira }\end{array}$ & $\mathrm{nM}$ & $\begin{array}{c}\text { Espectrofotométrico 2120 C } \\
\text { (APHA, 2005) }\end{array}$ & Espectrofotômetro UV-VIS & $\pm 0,1 \%$ \\
\hline
\end{tabular}

Fonte: Autores (2017)

\section{RESULTADOS E DISCUSSÃO}

\subsection{Calibração do aparato experimental}

A calibração do aparato experimental permitiu a produção de ozônio em $\mathrm{g} / \mathrm{h}$ para cada vazão era aplicada. Para a vazão de $60 \mathrm{~L} / \mathrm{h}$, são produzidos $2,07 \mathrm{gO}_{3} / \mathrm{h}$; para 120 $\mathrm{L} / \mathrm{h}$, são produzidos $4,29 \mathrm{gO}_{3} / \mathrm{h}$; para $180 \mathrm{~L} / \mathrm{h}$, são produzidos $5,38 \mathrm{gO}_{3} / \mathrm{h}$; para $240 \mathrm{~L} / \mathrm{h}$, são produzidos $6,16 \mathrm{gO}_{3} / \mathrm{h}$ e para $300 \mathrm{~L} / \mathrm{h}$ são produzidos $7,15 \mathrm{gO}_{3} / \mathrm{h}$.

\subsection{Caracterização do efluente sintético}

As características físico-químicas do efluente bruto utilizado na ozonização convencional estão representadas em função dos valores médios obtidos nas análises em triplicata para $\mathrm{pH}$, cor, turbidez e DQO, respectivamente: 7,8; $176 \mathrm{nM} ; 6,38 \mathrm{NTU}$ e 


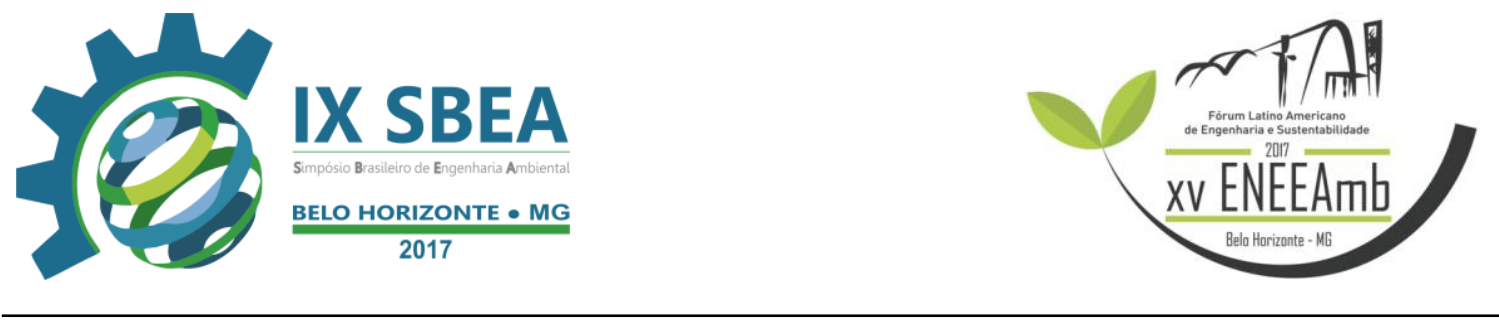

$320,6 \mathrm{mg} / \mathrm{L}$.

\subsection{Resultados da Ozonização}

A Figura 2 ilustra os valores médio dos parâmetros e suas respectivas eficiências de remoção para as diferentes vazões aplicadas.

Figura 2 - Valores médios de cor, turbidez e DQO e eficiências de remoção na ozonização convencional do efluente em $\mathrm{pH}$ in natura, para vazão de: (a) $60 \mathrm{~L} / \mathrm{h}$, (b) $120 \mathrm{~L} / \mathrm{h}$, (c) $180 \mathrm{~L} / \mathrm{h}$, (d) $240 \mathrm{~L} / \mathrm{h}$ e (e) $300 \mathrm{~L} / \mathrm{h}$.

(a)

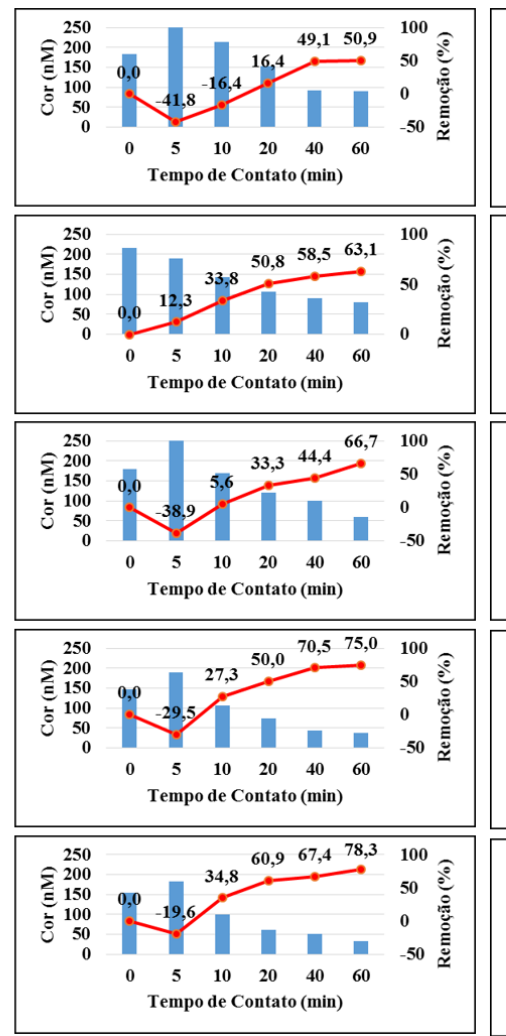
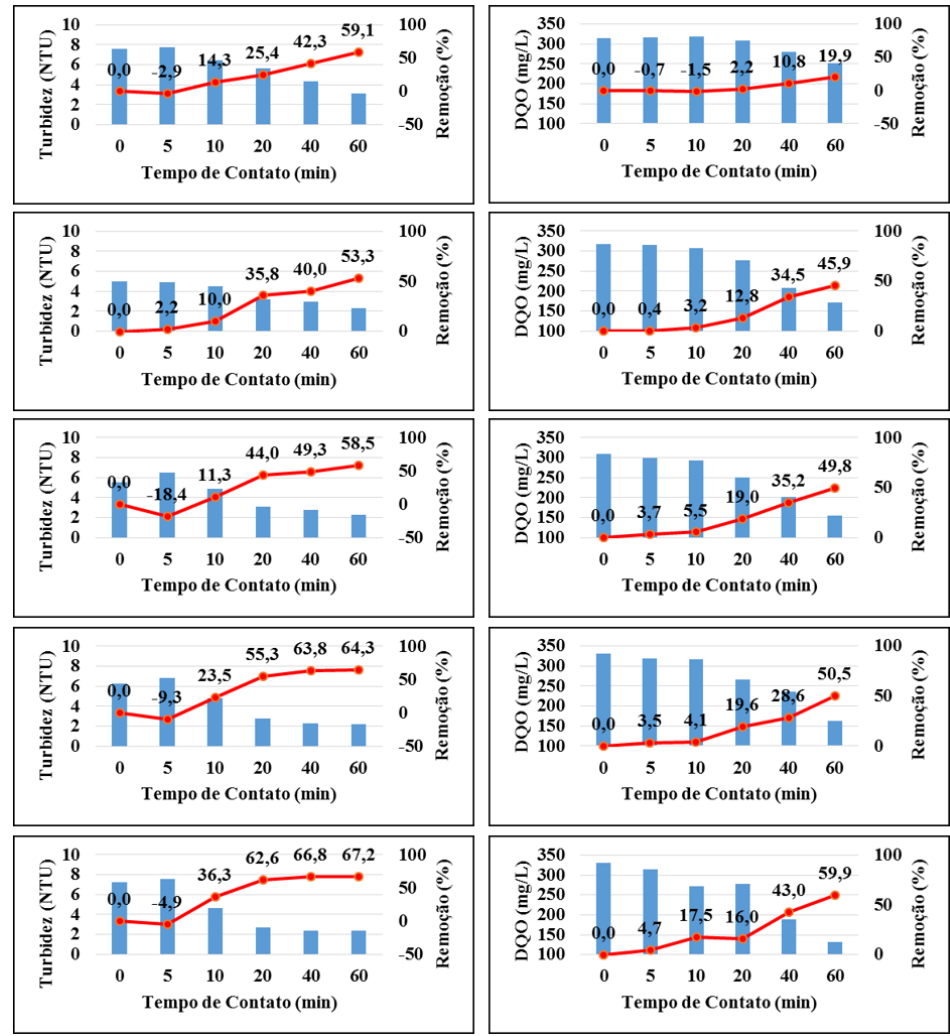

Fonte: Autores (2017)

Foi possível perceber que todos os parâmetros tiveram sua eficiência de remoção elevada com o acréscimo da vazão e do tempo de contato. O que pode ser explicado pelo fato de maiores vazões produzirem maior quantidade de ozônio, como pode ser visto na Figura 2. O maior tempo de contato entre as bolhas ascensionais e o efluente aumentam o tempo de reação do ozônio com os poluentes, gerando uma maior remoção 


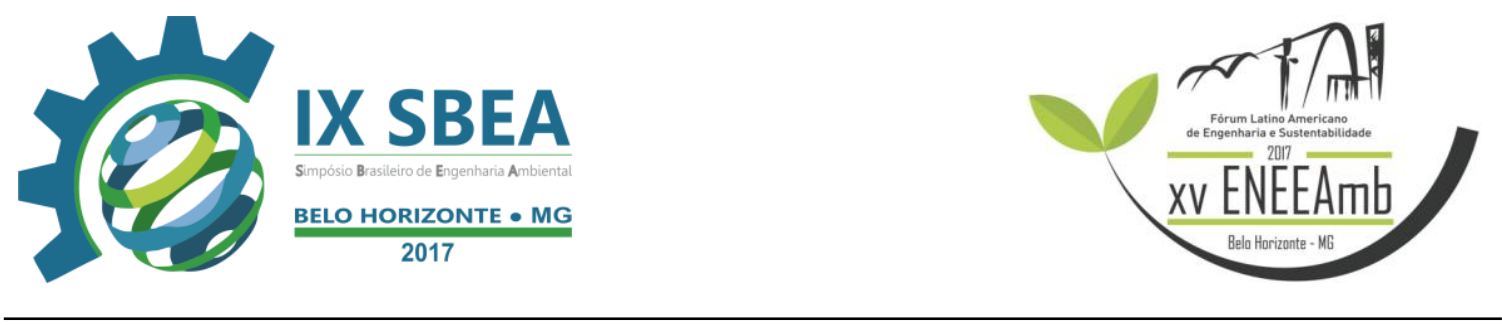

destes. Dessa maneira, todos os parâmetros apresentaram maior eficiência de remoção na configuração em que se aplicou $300 \mathrm{LO}_{3} / \mathrm{h}$ por 60 minutos.

A maior remoção foi de $78,3 \%$ de cor, que passou de 153,3 para $33,3 \mathrm{nM}$. O valor alcançado na melhor configuração para remoção de cor está dentro do limite máximo estabelecido pela CONAMA 357/2005 para todas as classes de uso de água, que é de $75 \mathrm{nM}$.

A melhor remoção turbidez foi de $67,2 \%$, que passou de 7,3 para 2,37 NTU. Não há legislação ambiental que preconize limites de turbidez, de qualquer forma, a expressiva remoção deste parâmetro é importante para que esgotos de melhor qualidade sejam lançados nos corpos hídricos, acelerando a autodepuração em ambientes lênticos e lóticos.

A maior remoção de DQO foi de 59,88\%, na qual este parâmetro passou de 330 para $132,67 \mathrm{mg} / \mathrm{L}$. Este valor está dentro do limite máximo estabelecido pela COPAM 01/2008 para lançamento de esgotos domésticos, que é de $180 \mathrm{mg} / \mathrm{L}$.

Os parâmetros cor e turbidez sofreram um aumento e uma consequente remoção negativa no tempo de 5 minutos para as vazões de 60, 180, 240 e $300 \mathrm{~L} / \mathrm{h}$. Cabe destacar que o efluente estudado não apresenta homogeneidade, devido a presença de óleo. Ao fazer o efluente e misturá-lo com espátula em um balde, a possibilidade de misturar completamente todos os constituintes é baixa. O substrato é quase uma emulsão e se mal misturado, o óleo permanece na superfície. As coletas eram realizadas pela torneira da parte inferior da coluna, dessa forma, ao se coletar o "branco", possivelmente coletou-se uma parte do efluente com menos óleo, o que não corresponde ao efluente como um todo. Os primeiros 5 minutos de borbulhamento de ozônio promoveram uma mistura do efluente, fazendo com que ele ficasse mais homogêneo e apresentasse as reais características do substrato. Mesmo em pequena quantidade, o óleo é o maior responsável pela conferência de cor e turbidez ao efluente. Dessa forma, justifica-se a remoção negativa no tempo 5 . Na vazão de $120 \mathrm{~L} / \mathrm{h}$ não houveram remoções negativas pois houve um atraso na coleta do "branco", que foi coletado poucos minutos após o borbulhamento do gás ter promovido a mistura do substrato. 


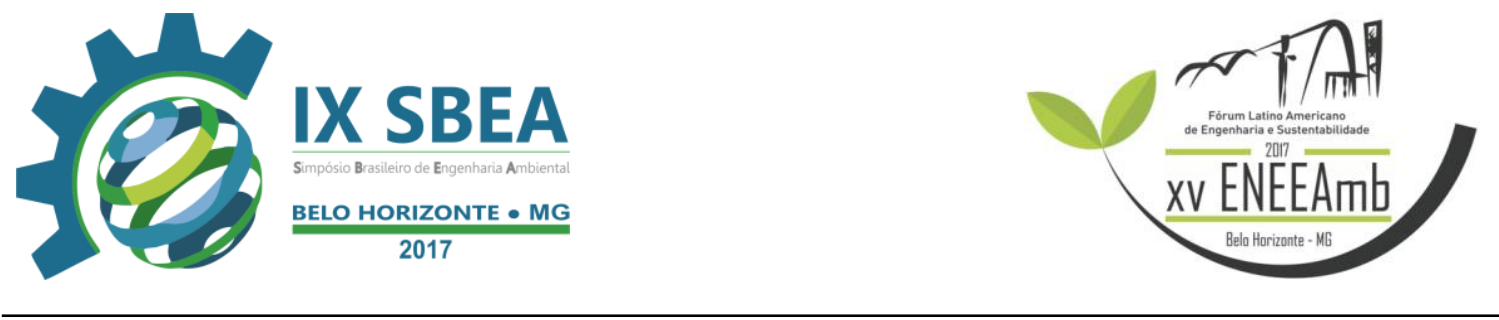

A eficiência de remoção de turbidez no tempo de 60 minutos na vazão de 120 $\mathrm{L} / \mathrm{h}$ não seguiu a tendência dos valores de remoção dos outros tempos. A remoção no tempo 60 na vazão de 120 foi de 53,3\%, menor do que a porcentagem de 59,1 da vazão de $60 \mathrm{~L} / \mathrm{h}$, contrariando a tendência de maiores remoções para maiores vazões. Este fato pode ser explicado pelo baixo consumo de ozônio durante o processo de ozonização na vazão de $120 \mathrm{~L} / \mathrm{h}$, conforme podemos ver no item 4.1, o consumo de ozônio nesta vazão não seguiu a tendência linear encontrada nas outras vazões. Esse baixo consumo pode ser um defeito pontual do próprio aparato experimental, que produziu menos ozônio do que o esperado nesta vazão.

\section{CONCLUSÕES/RECOMENDAÇÕES}

O processo de ozonização convencional se mostrou eficiente na descoloração do efluente, na redução da turbidez, na descoloração do efluente e na remoção da matéria orgânica carbonácea, podendo, futuramente, ser expandido ao tratamento do efluente real correspondente.

Como recomendação para trabalho futuro sugere-se realizar a homogeneização do efluente com o borbulhamento de gás inerte previamente às coletas; estudar o arraste de gases e quantificar a real oxidação de matéria orgânica promovida pela ozonização; estudar os efeitos da ozonização em diferentes $\mathrm{pH}$ e estudar a eficiência da ozonização com uso de catalisadores.

\section{REFERÊNCIAS BIBLIOGRÁFICAS}

APHA, AWWA; WPCF (1998). Standards Methods For Examination Of Water And Wastewater (1995). 20th ed. Amer. Public Health Association, American Water Works Association, Water Environment Federation, Washington, D. C. USA.

BERNAL-MARTINEZ A, Carrere H, Patureau D, Delgenes JP (2007). Ozone pretrestment as improver of $\mathrm{PAH}$ removal during anaerobic digestion of urban sludge. Chemosphere 68:1013-1019.

BRASIL. Ministério do Meio ambiente, Conselho Nacional do Meio ambiente, CONAMA. Resolução CONAMA no 357 de 17 de março de 2005. Disponível em: < http://www.mma.gov.br/port/conama/legiabre.cfm?codlegi=459> Acesso em: 29 de 


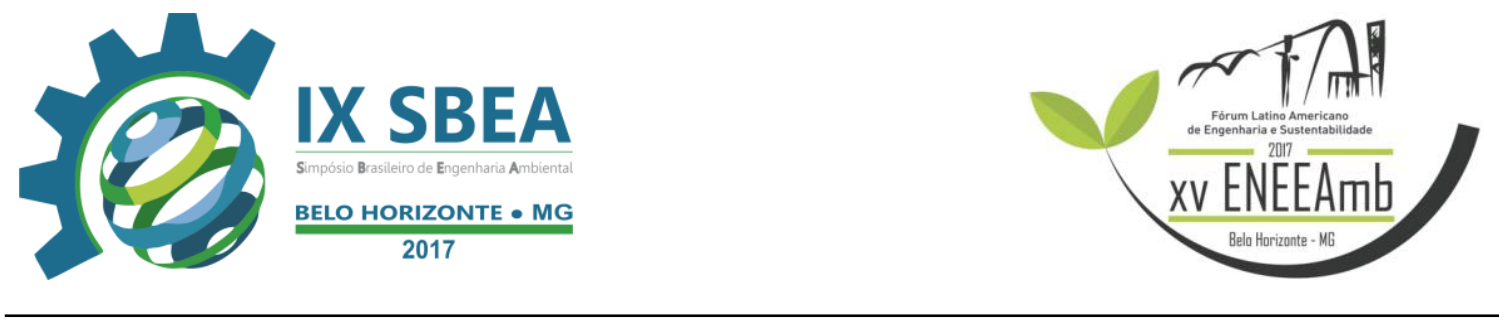

abril de 2017.

BRASIL. Ministério do Meio ambiente, Conselho Nacional do Meio ambiente, CONAMA. Resolução CONAMA no 430 de 13 de maio de 2011. Disponível em: < http://www.mma.gov.br/port/conama/legiabre.cfm?codlegi=646> Acesso em: 29 de abril de 2017.

COPAM/CERH-MG - Conselho de Política Ambiental de Minas Gerais e Conselho Estadual de Recursos Hídricos. Legislação do Meio Ambiente. Deliberação Normativa 01/2008. Belo Horizonte: 2008

GARRAFA, P. Avaliação da qualidade virológica do efluente doméstico tratado e disponibilizado para reuso na cidade de São Paulo. 2009. Tese de Doutorado. Universidade de São Paulo, São Paulo.

METCALF \& EDDY (2002). Wastewater engineering treatment and reuse. New York: McGraw-Hill, 4. ed., 1819 p.

OLIVEIRA, A. S. Tratamento de esgoto pelo sistema de lodos ativados no município de Ribeirão Preto, SP: avaliação da remoção de metais pesados. 2006. 172f. Dissertação (Mestrado) - Escola de Enfermagem de Ribeirão Preto, Universidade de São Paulo, Ribeirão Preto.

SOARES, L. V. Ozonização de esgoto sanitário: estudo da hidrodinâmica, transferência de massa e inativação de microrganismos indicadores. 2007. Tese de Doutorado - Escola de Engenharia de São Carlos, Universidade de São Paulo, São Carlos.

VON SPERLING, M. Princípios do Tratamento Biológico de Águas Residuárias: Introdução à Qualidade das Águas e ao Tratamento de Efluentes. 4. ed. Belo Horizonte: Departamento de Engenharia Sanitária e Ambiental, Editora UFMG, 2014. 472 p. v.1.

WHITE, G.C. (1999). Handbook of Chlorination and Alternative Disinfectants. 4 ed. New York: Wiley-Interscience, John Wiley and Sons Inc. 